\title{
Anthropogenic effects on plant cover in the Tlemcen region (western Algeria)
}

\author{
Hassiba Stambouli-Meziane*, Mohamed Bouazza \\ Laboratory of Ecology and Natural Ecosystems Management, University of Tlemcen, Tlemcen, Algeria; \\ *Corresponding Author: madiocre@yahoo.fr
}

Received 1 March 2012; revised 6 April 2012; accepted 30 April 2012

\begin{abstract}
The present work is devoted to the study of broad physiological and ecological characteristics of anthropophytic species on the high steppe lands of the Tlemcen region. The bioclimatic analysis confirms the development of drought in this region with a dominance of spiny and/or toxic asylvatic: plant species of shrub and herbaceous size species. We used correspondence factor analysis (CFA) of the various factors causing degradation to better understand the complexity of this ecosystem, whose floristic composition was complemented by means of soil measurements (spectrum green/ecological spectrum). This analysis allowed us to identify five groups of anthropophytic species with in this highly degraded matorral. We show that this ecosystem is already showing symptoms of degradation, and propose a preservation policy for protecting ensuring the survival of native species under threat from human activities.
\end{abstract}

Keywords: Anthropophytic; Ascending Hierarchical Clustering; Correspondence Factor Analysis; Matorral; Phytosociology; Tlemcen Region

\section{INTRODUCTION}

Anthropophytic species are distributed all over the Tlemcen Mountains, particularly on the south-western side. This has been shown in recent studies by the Laboratory of Ecology and Ecosystems Management at the University of Tlemcen, which examined the physiognomic composition of the plant formations [1], the specific effects of pasture land colonization [2], the specific effects and influence of anthropophytic species [3], the state of the flora in the Tlemcen wilaya (province) [1].

We propose that plant cover of anthropophytic species [4] unquestionably plays a more important role in zones which are highly exposed to pasture land. For decades, the forested and pre-forested area of the Tlemcen region has experienced continuous degradation, due to the combined action of climate and man [5].

Climate change (Higher temperatures and less precipitation) [3] and semi-arid (dry summer) of the study area disrupt the delicate balance of vegetation [6]. (For example, increasingly high temperatures in summer have led to replacement of hygrophilous species by xerophytes).

Human actions combined è weak or total lacks of regeneration contribute to the establishment of stands of matorral at which any rapid appreciation seems excluded.

Depending on the nature of this climate zone, soil genesis undergoes a significant change. This is the action of high temperature during the dry season.

Soils in the study area (Table1) are part of Red Mediterranean soils characterized by the presence of some remnants of terra-rossa as Chamaerops humilis and Ampelodesma mauritanicum.

The action of man, and especially cattle, alters species composition by choosing species according to their degree

Table 1. Soil characteristics of the study sites.

\begin{tabular}{lccc}
\hline & Site 1 & Site 2 & Site 3 \\
\hline Substratum & Rocky & Rocky & Rocky \\
Plant cover (\%) & 60 & 50 & 65 \\
Aspect & Northeast & Northeast & Southwest \\
Sample depth (cm) & $0-35$ & $0-40$ & $0-35$ \\
Soil texture definition & Clay & Clay & Clay \\
\% Sand & 31.6 & 7.66 & 15.69 \\
\% Silt & 54 & 71 & 76.87 \\
\% Clay & 14.4 & 21.34 & 16.31 \\
\% CaCO 3 & 0.76 & 4.43 & 8.08 \\
\hline
\end{tabular}


of palatability. At this pressure is compounded by the phenomenon of trampling which completely destroys the soil structure and makes it sensitive to the action of erosion.

Man collects wood for various uses, practices cereal land cultivation and raises livestock (sheep and goats) on pasture land. All these actions, with time and expansion, have caused a noticeable destruction of the plant cover [7]. Under this permanent pressure, the forests became matorrals [7]. In turn, the matorrals became fragmented and degraded, giving way to spiny and/or toxic species [8]. In addition, many of the native species populations suffered significantly, even to the point of extinction in some cases [8].

The importance of anthropogenic pressure, in association with the climatic conditions, inevitably causes a reduction in soil fertility [9], which directly affects plant growth.

We used vegetation sampling, correspondence factor analysis and ascending hierarchical clustering to provide a comprehensive assessment of this highly degraded matorral, and develop a management policy for preservation of existing native vegetation.

\section{MATERIALS AND METHODS}

The study area is situated in the western part of the greater Tlemcen, in the Mansourah municipality between $34^{\circ} 38^{\prime} \mathrm{N}$ and $34^{\circ} 50^{\prime} \mathrm{N}$, and $1^{\circ} 20^{\prime} \mathrm{W}$ and $1^{\circ} 25^{\prime} \mathrm{W}$.
Three study sites were selected within this area (Figure 1).

Site 1 is located in the north-west of the urban district of Imama, next to the Tlemcen university complex, at an altitude of $720 \mathrm{~m}$. It is characterized by uneven relief, with chalky soil, which is quite shallow in some places. The vegetation is dominated by Urginea maritima, Calycotome spinosa and Ulex boivinii. Plant cover is $60 \%$.

Site 2 is located at an altitude of $750 \mathrm{~m}$, with more visible chalky rock than the first one. Here, recent deforestation is evident by the presence of species remains such as: Quercus ilex, Pistacia lentiscus and Olea europaea. Plant cover is $50 \%$.

Site 3 is located opposite the Sites 1 and 2 at an altitude of $760 \mathrm{~m}$; it is located in a hollow and receives greater rainfall due to the orographic effect. The vegetation is dominated by Urginea maritima, Calycotome spinosa, Ulex boivinii and Olea europaea, with some remnants of Quercus ilex. Plant cover is 65\%.

The climate is classified as semi-continental [10], with a temperature range of $25^{\circ} \mathrm{C}-35^{\circ} \mathrm{C}$, an annual minimum of $5.4^{\circ} \mathrm{C}$ in January and an annual maximum of $30.5^{\circ} \mathrm{C}$ in July. The EMBERGER pluviothermal Climagramme [11] ranges the Tlemcen region in the higher semi-arid level with a moderate winter season.

In order to determine the minimal sampling area. The minimum area for sampling varies according to the type of vegetation, but should be at least of the same size as

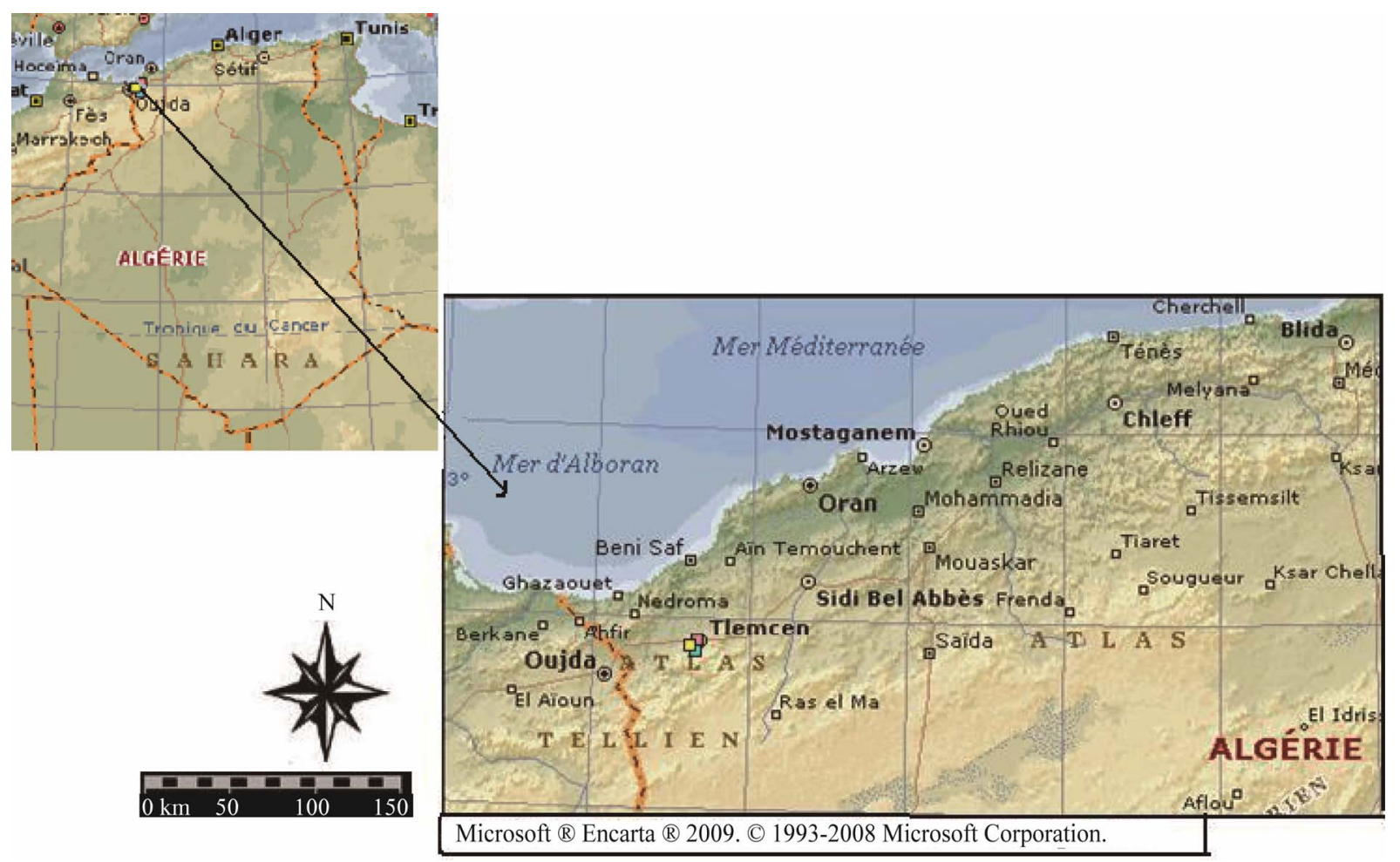

Figure 1. Location of study site. 
the minimal area defined by means of the "species-area curve" [6]. We found it difficult to determine a minimal area for the species in our study sites, because of the strong influence of the anthropogenic factor, and also the climatic factor (temperature) which contribute to altering their density on the one hand, and their distribution, on the other. Therefore, we selected a minimal area of 100 $\mathrm{m}^{2}$.

The floral survey was carried out throughout the entire vegetative period from March to August (1997-1999) on a number of plant formations in association with Quercus ilex, Olea europaea, Calycotome spinosa and Chamaerops humilis. We took into consideration the richest data at the floral level. i.e. where there is plenty of vegetation. The survey was conducted using the dominant abundance and sociability factors [12] that define the study sites (location, altitude, inclination, geomorphological substratum, average cover).

\section{RESULTS AND DISCUSSION}

Table 1 presents the data from the floristic survey. Correspondence factor analysis shows the main gradients differentiating between the three vegetation formations. Figure 2 presents the plot of Factors 1 and 2, and represents an anthropogenic gradient, dividing the vegetation into three groups: group A includes annual therophytic species; group B is dominated by anthropophytic species and finally, on the negative side; group $\mathrm{C}$ comprises species of pre-forest formations.

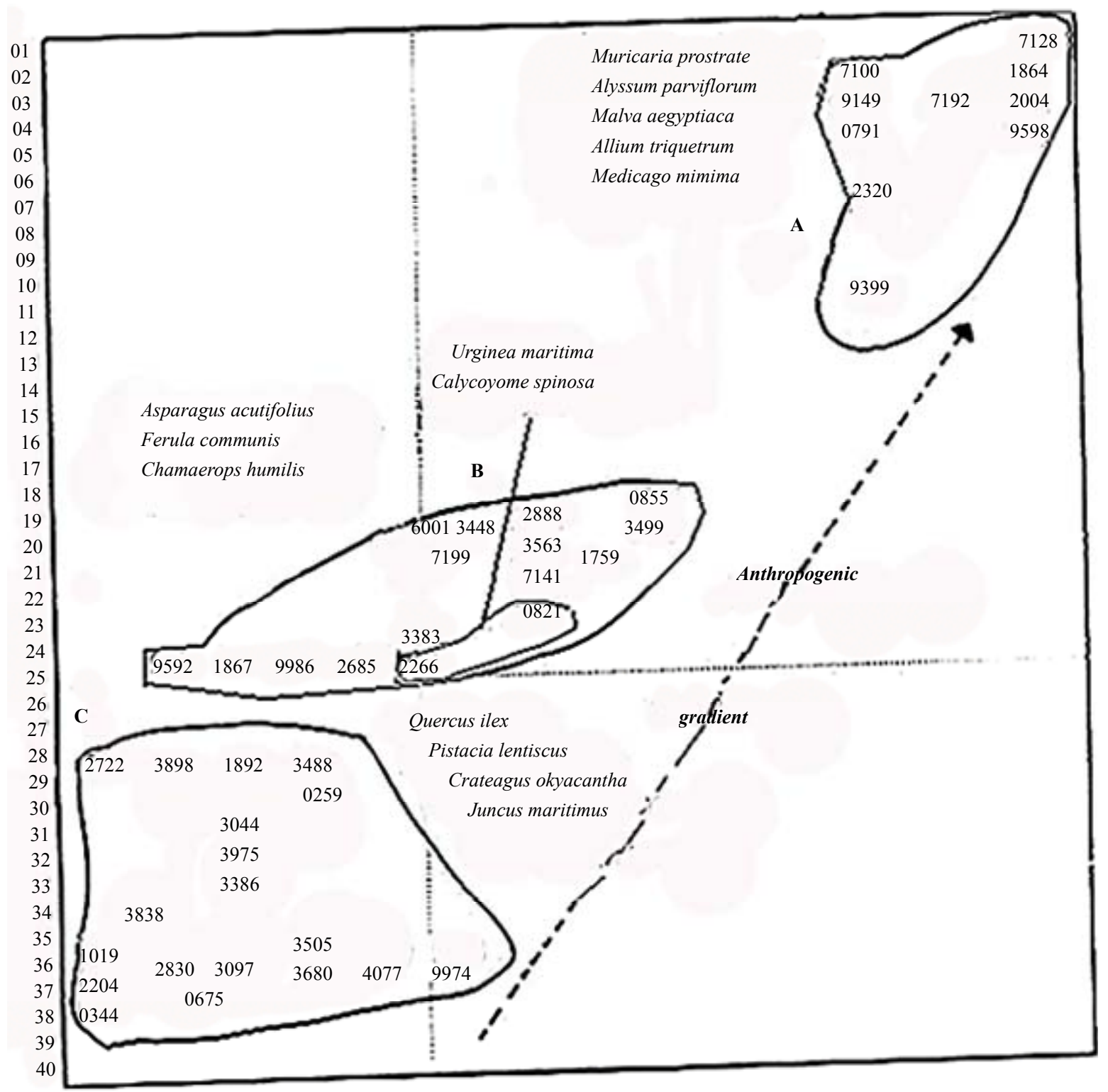

Figure 2. Chart relating to the factorial design (1-2) of the study zone species. 
Figure 3 presents the plots of Factors 1 and 3, representing a climatic gradient. The positive end of axis 3 is dominated by xerophytic species, whereas the negative end is dominated by hygrophilic pre-forest species. The anthropophytic species are still located mid-gradient.

These groupings are confirmed by the Ascending Hierarchical Clustering (Figure 4), which also includes Group D, comprising species that are not anthropophytic.

The results of the CFA allowed us to define five groups of anthropophytic species distributed across the three study sites, characterized by the following species:

Group I (moderate cattle trampling): Calycotome spinosa, Asparagus acutifolius;

Group II (heavy cattle trampling): Urginea maritima, Ulex boivinii, Ziziphus lotus, Ferula communis;
Group III (moderate cattle trampling): Calycotome spinosa, Ferula communis;

Group VI (moderate cattle trampling): Atractylis humilis, Atractylis carduus, Ulex boivinii;

Group V (heavy cattle trampling): Urginea maritima, Asparagus acutifolius, Ferula communis, Asphodelus microcarpus.

These common species constitute a particular assemblage associated with Chamaerops humilis. This species is very common, and its abundance increases in areas of intensive human and livestock activities.

The shrubby matorral vegetation formations are widely dispersed throughout the entire region, consisting of species foreign to the region. In these strongly degraded matorrals, the proliferation of the spiny and/or toxic species

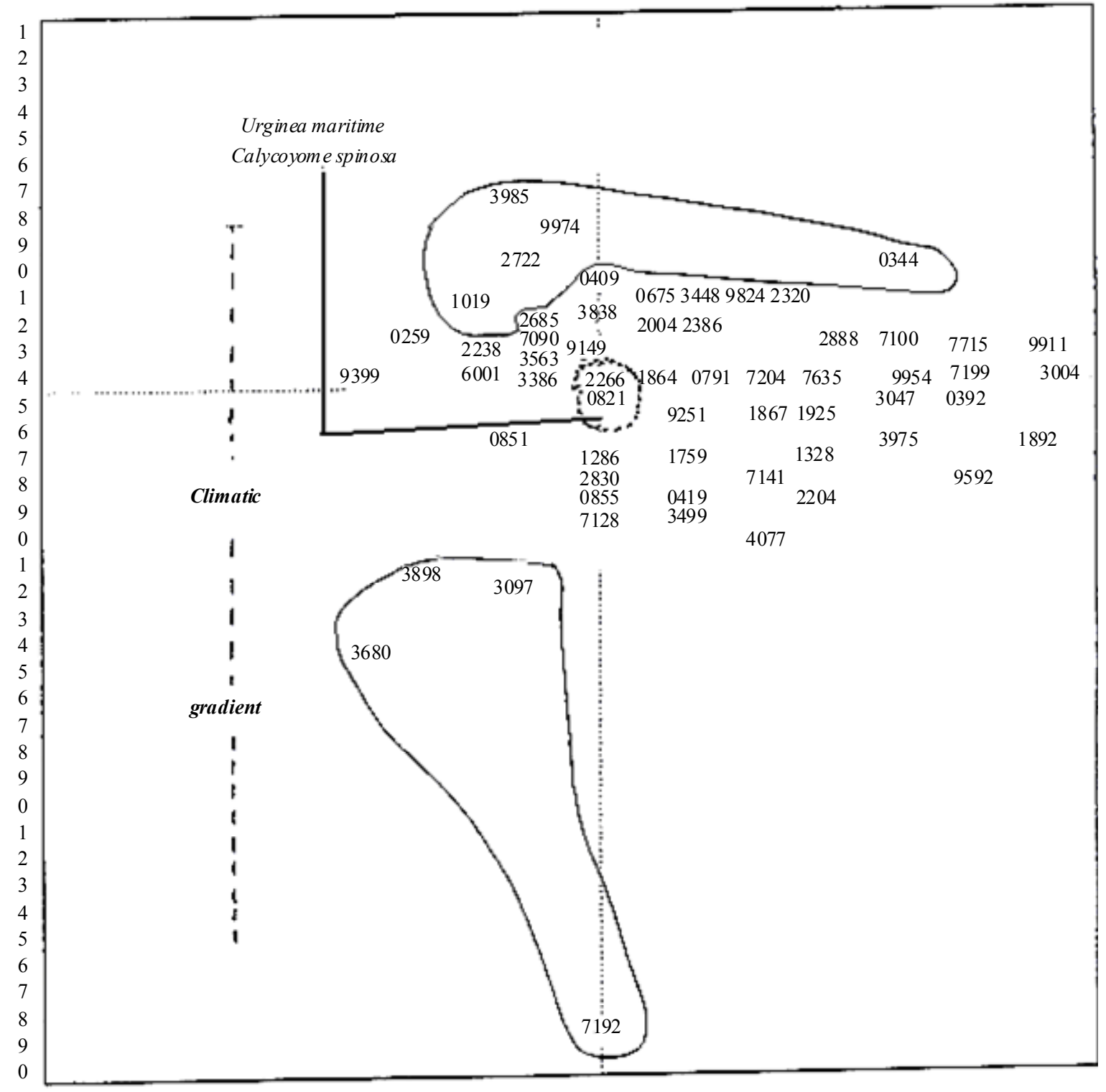

Figure 3. Chart relating to the factorial design (1-3) of the study zone species. 


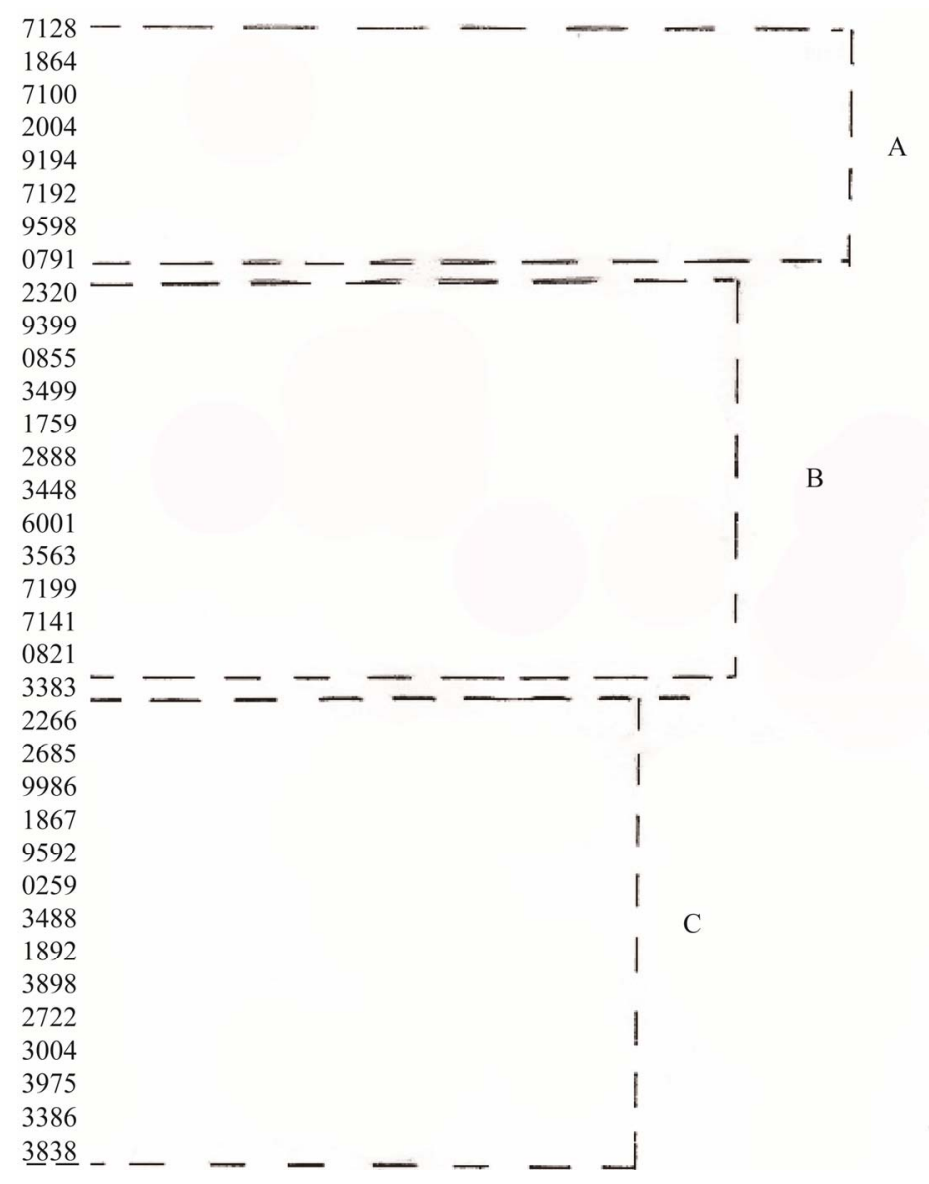

Figure 4. Ascending hierarchical clustering (C.A.H.).

constitutes the major floral grouping in our study sites. They are very abundant in easily accessible and level areas.

In contrast, there is, a great reduction of palatable species (relative to palatable species) such as Thymus ciliatus subsp coloratus, Lanvandula dentata and Ammoïdes verticillata. This phenomenon increases with the variation in temperature and rainfall, leading to earlier appearance of herds coming up from the south, and therefore constitutes an extinction factor of the humus.

These findings indicate a process of continuing degradation of the studied ecosystem. Currently, the survival of the palatable species in these Chamaerops zones strongly depends on the degree of anthropogenic pressure. It appears that a preservation policy is necessary to bring a satisfactory solution to this issue. It must necessarily ensure the protection of these species, but in addi tion, and most importantly, their natural habitats. The dangers of an impoverishment of the floral composition of the Tlemcen mountains and the steppe zones in the south of Tlemcen are real and may increase [8].

Humans and livestock, the primary causes of degradation, are extremely important and seriously disturb the equilibrium of these zones, causing observable and some- times irreversible degredation of this extremely fragile ecosystem.

During the past few years, animal and human pressure, which were already having a significant effect, increased in intensity in these natural areas [2]. Population growth, with its increasing needs, exerts strong anthropogenic pressure upon the region's natural resources. Over-exploitation of these resources has already caused serious problems in some regions, leading to processes of degradation of plant cover [8]. This degradation leads to local ecological disasters, e.g., increasingly active erosion, creeping sandbanks, more frequent floods, and scarcity of water supply [8]. Anthropogenic pressure also inevitably leads to significant population reduction of certain taxa, even to the point of extinction of some plant (The almost complete disappearance of Quercus ilex at the expense of such toxic species that Urginea maritima, Asphodelus microcarpus).

In the light of this situation, our main concern is the implementation of a policy to safeguard the vegetation under threat from anthropogenic pressure in the Tlemcen region. In order to achieve this objective, it is necessary to collect data about the flora and to make an inventory of extinct species and species under threat of extinction. 
The results of our study highlight the thoughtless actions of man in such an extremely fragile area. Urbanization of a number of ecosystems (steppe, forest or pre-forest), considered a few years ago as a solution to the housing problem or to industry, reveals its dangers today [12]. Of course, the danger varies between communities, but it remains noticeable. Moreover, the anarchic use of routes is also a crucial element in the degradation of plant cover. The role of urbanization in altering the vegetation structure deserves to be highlighted as it is clear that the urbanization methods selected by the authorities have led to serious degradation of plant cover in the region. In recent years, the presence of fire has further accelerated degradation of plant cover [5].

\section{CONCLUSIONS}

Anthropogenic pressure together with the climatic conditions (temperature factors) leads to impoverishment of plant cover and proliferation of spiny and/or toxic species which comprise the most important part of the floral grouping in our study sites. Thus we found clear symptoms of ecosystem degradation. Survival of the palatable species strongly depends on the degree of anthropogenic pressure. It appears that only a realistic preservation policy can bring a satisfactory solution to this issue, protecting not only the threatened species, but also their natural habitats.

It is, therefore, necessary to safeguard plant cover through processes of: intensification of fodder crop production, founding a pastoretum for their production, regulation and use of defined routes, defining rules on how to lead herds, and finally, following a breeding policy adapted to each zone or community.

\section{REFERENCES}

[1] Ainad, T.M. (1996) Analyses éco floristiques des grandes structures de végétation dans les monts de Tlemcen (Approche phytoécologique). Université de Tlemcen, Tlemcen.

[2] Benabadji, N. (1995) Etude phytoécologique des steppes à Artemisia herba-alba Asso. Et Salsola vermiculata L. au sud ouest de Sebdou (Oranie-Algérie). Ph.D. Thesis, Université de Tlemcen, Tlemcen.

[3] Benabdelli, K. (1983) Mise au point d'une méthodologie d'appréciation de la pression anthropozoogéne sur la végétation de la région de Telagh (Algérie). Ph.D. Thesis, Faculté des Sciences et Techniques de St-Jérôme, Marseille.

[4] Alcaraz, C. (1982) La végétation de l'ouest algérien. Université de Perpignan.

[5] Bouabdellah, H. (1992) Dégradation du couvert végétal steppique de la zone sud ouest oranais, cas d'El-Aricha. Université d'Oran, Oran.

[6] Gounot, M. (1969) Méthodes d'études quantitatives de la végétation. Ecologia-Mediterranea Université, Avignon.

[7] Benabadji, N. (1998) Contribution à une étude phytoécologique des Théro-brachypodietea dans la région de Tlemcen. Université de Tlemcen, Tlemcen.

[8] Bouazza, M. (1995) Etude phytoécologique des steppes à Stipa tenacissima L. et Lygeum spartum L. au sud ouest de Sebdou (Oranie, Algérie). Ph.D. Thesis, Université de Tlemcen, Tlemcen.

[9] Gaouar, A. (1980) Hypothèses et réflexions sur la dégradation des écosystèmes forestiers dans la région de Tlemcen (Algérie). Revue Forêt Méditerranéen, Marseille.

[10] Debrach, J. (1953) Notes sur le climat du Maroc Occidental. Maroc Médical, 32, 1122-1134.

[11] Emberger, L. (1952) Sur le quotient pluviothermique. Sciences, 234, 2508-2511.

[12] Braun-Blanquet, J. (1951) Pflauzensoziologie, grundzuge der végétations kunde. 2nd Edition, Springer, Vienne. 